\title{
Usefulness of the desaturation-distance ratio from the six-minute walk test for patients with COPD
}

This article was published in the following Dove Press journal: International Journal of COPD

6 September 2017

Number of times this article has been viewed
Purpose: A straightforward, noninvasive method is needed to assess emphysema and pulmonary hypertension ( $\mathrm{PH}$ ) in COPD patients. The desaturation-distance ratio (DDR) is an index derived from the distance traveled and level of desaturation during a six-minute walk test (6MWT); it has previously been shown to be associated with percentage of forced expiratory volume in the first second of expiration $\left(\% \mathrm{FEV}_{1.0}\right)$ and percentage of diffusion capacity of the lung for carbon monoxide (\%DLCO). The aim of this study was to examine the associations between DDR and emphysema and $\mathrm{PH}$.

Patients and methods: We collected the following data for 74 stable COPD outpatients: lung function tests $\left(\% \mathrm{FEV}_{1.0}\right.$ and $\left.\% \mathrm{DLCO}\right), 6 \mathrm{MWT}$ distance and desaturation, and area of emphysema on computed tomography (percentage of low attenuation area). Enlargement of the pulmonary artery (PA) was assessed by the ratio of the diameter of the PA to that of the aorta (PA:A ratio) as an index of PH. DDR was calculated by the distance traveled and the degree of desaturation reached during a 6MWT. The relationships between study outcomes were assessed with Spearman's rank-correlation analysis. Receiver operating characteristic (ROC) curves were used to determine the threshold values with the optimum cutoff points for predicting severe or very severe airway obstruction, pulmonary diffusing capacity disorder, moderate or severe emphysema, and enlargement of the PA.

Results: DDR correlated significantly with $\% \mathrm{FEV}_{1.0}, \% \mathrm{DLCO}, \% \mathrm{LAA}$, and PA:A ratio. DDR showed high accuracy (area under the ROC curve $>0.7$ ) for predicting severe or very severe airway obstruction, pulmonary diffusing capacity disorder, moderate or severe emphysema, and enlargement of the PA.

Conclusion: The results suggest that DDR is a good index of emphysema and $\mathrm{PH}$ in COPD patients. The 6MWT is widely used to assess COPD, and DDR could help with the early diagnosis of COPD.

Keywords: six-minute walk test, COPD, desaturation-distance ratio, exercise-induced oxygen desaturation, emphysema, pulmonary hypertension

\section{Introduction}

COPD is characterized by airflow obstruction and emphysema. ${ }^{1,2}$ These two conditions commonly coexist, often with different degrees of severity ${ }^{3}$ indeed, emphysema has been confirmed in smokers without airflow obstruction. ${ }^{4-7}$ Emphysema affects quality of life and has been shown to be associated with exacerbations of COPD and deteriorating pulmonary function. ${ }^{7}$ Pulmonary hypertension $(\mathrm{PH})$ is an important serious comorbidity of COPD, which has been shown to be associated with the exacerbation of COPD and mortality. ${ }^{8,9}$ Right heart catheterization (RHC) is the gold standard
Correspondence: Yukari Fujimoto Department of Community Health Sciences, Kobe University Graduate School of Health Sciences, 7-10-2,

Tomogaoka, Suma-ku, Kobe 654-0I42, Hyogo, Japan

Tel/fax +8I 787964526

Email yukari0826kkk@yahoo.co.jp
International Journal of COPD 2017:12 2669-2675

(c) (i) (8) () 2017 Fujimoto et al. This work is published and licensed by Dove Medical Press Limited. The full terms of this license are available at https://www.dovepress.com/terms.php cc. hereby accept the Terms. Non-commercial uses of the work are permitted without any further permission from Dove Medical Press Limited, provided the work is properly attributed. For permision for commercial use of this work, please see paragraphs 4.2 and 5 of our Terms (https://www.dovepress.com/terms.php). 
method for the diagnosis or evaluation of $\mathrm{PH},{ }^{10,11}$ but it can be difficult in practice to provide all COPD patients with $\mathrm{RHC}$ because of its high degree of invasiveness. ${ }^{9}$ The ratio of the diameter of the pulmonary artery (PA) to that of the aorta (PA:A ratio), measured by computed tomography (CT), is an index for enlargement of the PA, a condition independently related to exacerbations in COPD patients. ${ }^{12}$ The PA:A ratio has been reported to be superior to echocardiography in the diagnosis of resting $\mathrm{PH}$ in patients with severe COPD. ${ }^{13}$ Indeed, CT provides a range of information about COPD, including the extent of emphysema and $\mathrm{PH}$, but it cannot be used in all situations. An easier noninvasive method that takes account of the various manifestations of COPD is needed for early diagnosis.

The six-minute walk test (6MWT) is a straightforward and low-cost test used worldwide to evaluate the exercise capacity of patients with COPD. ${ }^{14}$ The six-minute walk distance (6MWD) and the degree of exercise-induced oxygen desaturation (EID) measured during the 6MWT have been shown to be related to emphysema and PH in COPD patients. ${ }^{15-18}$ The desaturation-distance ratio (DDR), calculated from the 6MWD and the degree of EID during the $6 \mathrm{MWT}$, has recently been proposed as an index for the assessment of interstitial lung disease. ${ }^{19}$ The DDR has been shown to be associated with pulmonary function in COPD patients, including the degree of airflow obstruction and pulmonary diffusing capacity. ${ }^{19,20}$ However, there have been no reports examining whether the DDR was related to the degree of emphysema or PH in COPD patients. The aim of this study, therefore, was to examine whether the DDR could be used to assess emphysema and $\mathrm{PH}$ in COPD patients.

\section{Patients and methods Study subjects}

The outpatients with stable COPD who visited Kobe City Medical Center West Hospital between 2014 and 2016 were enrolled in this study. The diagnosis of COPD was based on the following criteria: age $>40$ years, a smoking history of $\geq 20$ pack-years, and a ratio of the forced expiratory volume in the first second of expiration $\left(\mathrm{FEV}_{1.0}\right)$ to forced vital capacity $(\mathrm{FVC})<70 \%$. The subjects were classified according to the Global initiative for chronic Obstructive Lung Disease (GOLD) airflow limitation. In addition, clinical symptoms such as a chronic cough, sputum, or dyspnea and smoking history, and/or emphysema on CT were included in the physician's diagnosis of COPD at risk (GOLD stage 0), even if $\mathrm{FEV}_{1.0} / \mathrm{FVC}$ was $>70 \% .{ }^{21-25}$ The following exclusion criteria were applied: a previous lung surgical procedure, exacerbation for at least 3 months prior to undergoing the $6 \mathrm{MWT}$, inability to accurately perform the 6MWT, lung function test, and CT, and the use of long-term oxygen therapy. Figure 1 presents a flow diagram of subject enrollment. The study protocol was approved by the ethics committee of Kobe University (N287, Kobe, Japan). All subjects provided written or verbal informed consent.

\section{Data collection}

The following information was collected for each subject: age, sex, body mass index (BMI), modified Medical Research Council dyspnea score, and smoking history in pack-years. In addition, each subject performed the 6MWT and underwent a lung function test and a CT scan to assess the extent of emphysema and evaluate the PA:A ratio.

\section{Six-minute walk test}

The 6MWT was administered according to the American Thoracic Society (ATS) guidelines. ${ }^{26}$ It was performed indoors on a flat square course with 25-m long sides, supervised by a physician and a physical therapist. Each subject was asked to walk as far as possible around the course in six minutes, during which the modified Borg scale was recorded each minute as a measure of dyspnea. Every two seconds, peripheral oxygen saturation $\left(\mathrm{SpO}_{2}\right)$ and pulse rate were recorded using WristOx (model 3150; Nonin Medical, Plymouth, MN, USA); these data were analyzed by WristOx2 software (Star Product, Tokyo, Japan).

The DDR was calculated as the ratio of the desaturation area (DA) to the 6MWD. We used two versions of the DDR (DDR-original and DDR-simple) based on different

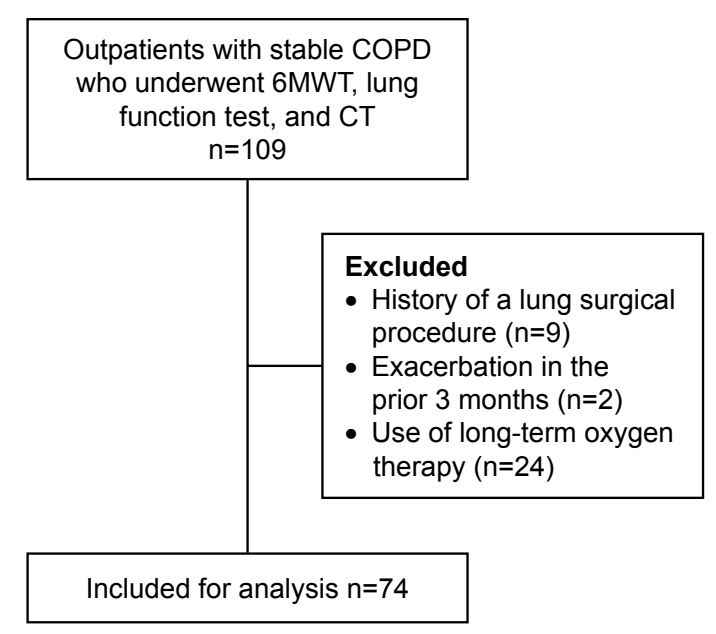

Figure I Subject enrollment.

Abbreviations: $6 \mathrm{MWT}$, six-minute walk test; $\mathrm{CT}$, computed tomography. 
ways of calculating DA as proposed in previous studies. ${ }^{19,20}$ For DDR-original, DA was obtained from the sum of the differences between $100 \%$ and the recorded $\mathrm{SpO}_{2}$ sampled every two seconds. ${ }^{19}$ For DDR-simple, DA was obtained from the sum of the differences between $100 \%$ and the recorded $\mathrm{SpO}_{2}$ sampled once a minute. ${ }^{20}$

\section{Lung function test}

The lung function test was performed according to the ATS guidelines $^{27}$ and measured $\mathrm{FVC}, \mathrm{FEV}_{1.0}$, and the diffusion capacity of the lung for carbon monoxide (DLCO). Each was expressed as percentages of the predicted values $(\% \mathrm{FVC}$, $\% \mathrm{FEV}_{1.0}$, and $\% \mathrm{DLCO}$, respectively).

\section{Extent of emphysema and PA:A ratio}

CT was performed using Optima CT 660 Discovery (GE Healthcare, Little Chalfont, UK). Emphysema was identified by the percentage of low attenuation area (\%LAA) across all lung fields. ${ }^{28-30}$ The Goddard Score was used as an index of the severity of emphysema. ${ }^{31}$

Measurement of the PA:A ratio followed the method described in previous studies. ${ }^{12,13}$ The diameters of the PA and the aorta at the level of the bifurcation were measured on CT images. Because the diameter of the aorta was not uniform across different measurement points, two measurements were taken $90^{\circ}$ apart, and the larger diameter was used in the analysis. The diameter of the PA was measured on the line joining the origin of the left PA to the center of the adjacent ascending aorta on the axial section. Enlargement of the PA was defined as PA:A ratio $>1 .{ }^{13}$

\section{Statistical analysis}

The statistical analyses were performed with EZR (Saitama Medical Center, Jichi Medical University, Saitama, Japan). $p$-values $<0.05$ were considered to be significant. Data are presented as counts, percentages, or medians with the range or interquartile range.

Cohen's $\kappa$-coefficient was used to evaluate the intraobserver and interobserver reliability for detecting PA:A ratio $>1$. Spearman's rank-correlation analysis was used to assess the relationship between study outcomes in the subjects and $\mathrm{FEV}_{1.0} / \mathrm{FVC}<70 \%$. Receiver operating characteristic (ROC) curves were used to calculate the optimum cutoff values to predict $\% \mathrm{FEV}_{1.0}<50 \%$ as an index of severe or very severe airway obstruction, ${ }^{1} \% \mathrm{DLCO}<75 \%$ as an index of pulmonary diffusing capacity disorder, ${ }^{3,25}$ Goddard Score $\geq 8$ as an index of moderate or severe emphysema, ${ }^{31}$ and $\mathrm{PA}:$ A ratio $>1$ as an index of $\mathrm{PH} .{ }^{13}$ The optimum cutoff values were defined as the point on the ROC curve closest to the upper-left corner of the chart.

\section{Results}

The final analysis included 74 subjects (16 women and 58 men). Table 1 presents the subjects' characteristics. The median age was 73 (range 67-78) years, the median BMI was $22.0(19.9-23.8) \mathrm{kg} / \mathrm{m}^{2}$, and the median $\% \mathrm{FEV}_{1.0}$ was $63.6 \%(47.0 \%-76.1 \%)$, with 25 of the subjects having $\mathrm{FEV}_{1.0}$ FVC $\geq 70 \%$. The $\kappa$-values for intraobserver and interobserver reliability for detecting PA:A ratio $>1$ were 0.75 (95\% confidence interval [CI] 0.57-0.92) and 0.71 (95\% CI 0.53-0.90), respectively.

Table I Characteristics of the subjects

\begin{tabular}{|c|c|}
\hline Characteristic & All patients $(n=74)$ \\
\hline Age (years) & $73(67-78)$ \\
\hline Sex, female (\%) & $16(21.6)$ \\
\hline $\mathrm{FEV}_{1.0} / \mathrm{FVC} \geq 70 \%(\%)$ & $25(33.8)$ \\
\hline BMI $\left(\mathrm{kg} / \mathrm{m}^{2}\right)$ & $22.0(19.9-23.8)$ \\
\hline Smoking (pack-years) & $45.5(30.8-60.0)$ \\
\hline GOLD $(0 / 1 / 2 / 3 / 4)$ & $25 / 7 / 23 / 17 / 2$ \\
\hline $\operatorname{mMRC}(0 / 1 / 2 / 3 / 4)$ & $0 / 13 / 50 / 10 / 1$ \\
\hline \multicolumn{2}{|l|}{ Medication } \\
\hline LABA (\%)/LAMA (\%)/ICS (\%) & $44(59.4) / 44(59.4) / 22(29.7)$ \\
\hline \%FVC (\%) & $80.7(66.7-89.1)$ \\
\hline$\% \mathrm{FEV}_{1.0}(\%)$ & $63.6(47.0-76.1)$ \\
\hline \%DLCO (\%) & $55.5(43.4-72.6)$ \\
\hline \%LAA (\%) & I2.3 (3.9-24.9) \\
\hline Goddard Score & $5.5(I-9)$ \\
\hline PA:A ratio & $0.94(0.80-1.03)$ \\
\hline PA:A ratio > I (\%) & $33(44.6)$ \\
\hline 6MWD (m) & $4 I I(325-479)$ \\
\hline Baseline $\mathrm{SpO}_{2}(\%)$ & $96(95-97)$ \\
\hline Lowest $\mathrm{SpO}_{2}(\%)$ & 91 (86-93) \\
\hline$\Delta \mathrm{SpO}_{2}(\%)$ & $4.5(3.0-8.0)$ \\
\hline Baseline PR (bpm) & $75(69-85)$ \\
\hline Highest PR (bpm) & $108(100-115)$ \\
\hline$\Delta \mathrm{PR}(\mathrm{bpm})$ & $30(24-38)$ \\
\hline Baseline BS & $0(0-0)$ \\
\hline Highest BS & $3(0.5-5)$ \\
\hline DA-original & $1,294(9|4-1,84|)$ \\
\hline DA-simple & $45(3 \mid-64)$ \\
\hline DDR-original & $2.9(2.1-5.2)$ \\
\hline DDR-simple & $0.11(0.07-0.18)$ \\
\hline
\end{tabular}

Notes: Data are presented as median (interquartile range) or count (\%). $\Delta \mathrm{SpO}$ was defined as the change from baseline to the lowest $\mathrm{SpO}_{2}$. $\Delta \mathrm{PR}$ was defined as the change from baseline to the highest PR.

Abbreviations: $\mathrm{FEV}_{1.0}$, forced expiratory volume in the first second of expiration; FVC, forced vital capacity; BMI, body mass index; GOLD, Global initiative for chronic Obstructive Lung Disease; mMRC, modified Medical Research Council dyspnea score; LABA, long-acting $\beta_{2}$ agonist; LAMA, long-acting muscarinic antagonist; ICS, inhaled corticosteroid; DLCO, diffusion capacity of the lung for carbon monoxide; LAA, low attenuation area; PA, pulmonary artery; A, aorta; 6MWD, six-minute walk distance; $\mathrm{SpO}_{2}$, peripheral oxygen saturation; $\mathrm{PR}$, pulse rate; $\mathrm{BS}$ modified Borg scale; DA, desaturation area; DDR, desaturation-distance ratio. 
Table 2 Linear correlations of the DDR and 6MWT outcomes with the factors of COPD

\begin{tabular}{|c|c|c|c|c|c|c|c|c|}
\hline & \multicolumn{2}{|c|}{$\% \mathrm{FEV}_{1.0}$} & \multicolumn{2}{|c|}{$\%$ DLCO } & \multicolumn{2}{|l|}{ \%LAA } & \multicolumn{2}{|c|}{ PA:A ratio } \\
\hline & $r$ & $p$-value & $r$ & $p$-value & $r$ & $p$-value & $r$ & $p$-value \\
\hline \multicolumn{9}{|l|}{ All subjects } \\
\hline DDR-original & -0.312 & 0.006 & -0.497 & $<0.001$ & 0.381 & 0.001 & 0.553 & $<0.001$ \\
\hline DDR-simple & -0.317 & 0.006 & -0.518 & $<0.001$ & $0.4 I I$ & $<0.001$ & 0.567 & $<0.001$ \\
\hline 6MWD (m) & 0.205 & 0.079 & 0.360 & 0.001 & 0.078 & 0.519 & -0.340 & 0.003 \\
\hline Lowest $\mathrm{SpO}_{2}(\%)$ & 0.227 & 0.068 & 0.400 & $<0.001$ & -0.542 & $<0.001$ & -0.562 & $<0.001$ \\
\hline \multicolumn{9}{|c|}{ Subjects with $\mathrm{FEV}_{1.0} / \mathrm{FVC}<70 \%$} \\
\hline DDR-original & -0.438 & 0.001 & -0.569 & $<0.001$ & 0.350 & 0.016 & 0.444 & 0.001 \\
\hline DDR-simple & -0.455 & 0.001 & -0.586 & $<0.001$ & 0.373 & 0.010 & 0.459 & $<0.001$ \\
\hline 6MWD (m) & 0.313 & 0.043 & 0.435 & 0.001 & 0.102 & 0.497 & -0.306 & 0.032 \\
\hline Lowest $\mathrm{SpO}_{2}(\%)$ & 0.348 & 0.014 & 0.417 & 0.002 & -0.546 & $<0.001$ & -0.459 & $<0.001$ \\
\hline
\end{tabular}

Note: Spearman's rank-correlation analysis was used to assess the correlations.

Abbreviations: DDR, desaturation-distance ratio; $6 \mathrm{MWT}$, six-minute walk test; $\mathrm{FEV}_{1.0}$, forced expiratory volume in the first second of expiration; DLCO, diffusion capacity of the lung for carbon monoxide; LAA, low attenuation area; PA, pulmonary artery; A, aorta; 6MWD, six-minute walk distance; SpO ${ }_{2}$, peripheral oxygen saturation; FVC, forced vital capacity.

Table 2 presents the results of the linear correlation analysis. DDR-original and DDR-simple correlated significantly with $\% \mathrm{FEV}_{1.0}(r=-0.312, p=0.006$ and $r=-0.317$, $p=0.006$, respectively), \%DLCO $(r=-0.497, p<0.001$ and $r=-0.518, p<0.001$, respectively), \%LAA ( $r=0.381$, $p=0.001$ and $r=0.411, p<0.001$, respectively), and PA:A ratio $(r=0.553, p<0.001$ and $r=0.567, p<0.001$, respectively). 6MWD correlated significantly with \%DLCO $(r=0.360, p=0.001)$ and PA:A ratio $(r=-0.340, p=0.003)$. The lowest level of $\mathrm{SpO}_{2}$ correlated significantly with $\% \mathrm{DLCO}$ $(r=0.400, p<0.001), \%$ LAA $(r=-0.542, p<0.001)$, and PA:A ratio $(r=-0.562, p<0.001)$. DDR-original and DDRsimple showed stronger correlations with $\% \mathrm{FEV}_{1.0}$ for the subjects with $\mathrm{FEV}_{1.0} / \mathrm{FVC}<70 \%$ ( $r=-0.438, p=0.001$ and $r=-0.455, p=0.001$, respectively) than for all the subjects. $6 \mathrm{MWD}$ and lowest $\mathrm{SpO}_{2}$ both correlated significantly with $\% \mathrm{FEV}_{1.0}$ for the subjects with $\mathrm{FEV}_{1.0} / \mathrm{FVC}<70 \%(r=0.313$, $p=0.043$ and $r=0.348, p=0.014$, respectively).

Table 3 shows the results of the ROC analysis. DDRoriginal, DDR-simple, and lowest $\mathrm{SpO}_{2}$ all showed high accuracy (area under the ROC curve $[\mathrm{AUC}]>0.7$ ) for predicting $\% \mathrm{FEV}_{1.0}<50 \%, \% \mathrm{DLCO}<75 \%$, Goddard Score $\geq 8$, and PA:A ratio $>1$. The threshold values to predict $\% \mathrm{FEV}_{1.0}<50 \%$ were determined for DDR-original (best cutoff point 4.0 , AUC $0.73,95 \%$ CI $0.62-0.85$ ), DDR-simple (best cutoff point 0.14 , AUC $0.74,95 \%$ CI 0.63-0.85), and lowest $\mathrm{SpO}_{2}$ (best cutoff point 89, AUC $0.72,95 \%$ CI $0.60-0.84)$. The threshold values to predict $\%$ DLCO $<75 \%$ were determined for DDR-original (best cutoff point 2.7, AUC 0.78, 95\% CI 0.64-0.91), DDR-simple (best cutoff point 0.09 , AUC $0.79,95 \%$ CI $0.66-0.93$ ), and lowest $\mathrm{SpO}_{2}$ (best cutoff point 91, AUC 0.75, 95\% CI
0.61-0.89). The threshold values to predict Goddard Score $\geq 8$ were determined for DDR-original (best cutoff point 4.0, AUC 0.71, 95\% CI 0.59-0.83), DDR-simple (best cutoff point 0.09 , AUC $0.73,95 \%$ CI $0.62-0.85$ ), and lowest $\mathrm{SpO}_{2}$ (best cutoff point 90, AUC 0.79, 95\% CI 0.68-0.89). The threshold values to predict PA:A ratio $>1$ were determined for DDR-original (best cutoff point 2.8, AUC 0.82,

Table 3 The optimum cutoff and ROC curve parameters for the prediction of factors related to COPD

\begin{tabular}{|c|c|c|c|c|c|}
\hline & Cutoff & Sensitivity & Specificity & AUC & $95 \% \mathrm{Cl}$ \\
\hline \multicolumn{6}{|l|}{$\% \mathrm{FEV}_{1.0}<50 \%$} \\
\hline DDR-original & 4.0 & 0.74 & 0.71 & 0.73 & $0.62-0.85$ \\
\hline DDR-simple & 0.14 & 0.72 & 0.71 & 0.74 & $0.63-0.85$ \\
\hline 6MWD (m) & 395 & 0.68 & 0.62 & 0.65 & $0.5 \mathrm{I}-0.79$ \\
\hline Lowest $\mathrm{SpO}_{2}(\%)$ & 89 & 0.70 & 0.67 & 0.72 & $0.60-0.84$ \\
\hline \multicolumn{6}{|l|}{$\%$ DLCO $<75 \%$} \\
\hline DDR-original & 2.7 & 0.88 & 0.66 & 0.78 & $0.64-0.91$ \\
\hline DDR-simple & 0.09 & 0.88 & 0.73 & 0.79 & $0.66-0.93$ \\
\hline 6MWD (m) & 375 & 0.88 & 0.45 & 0.63 & $0.49-0.77$ \\
\hline Lowest $\mathrm{SpO}_{2}(\%)$ & 91 & 0.81 & 0.68 & 0.75 & $0.6 \mathrm{I}-0.89$ \\
\hline \multicolumn{6}{|l|}{ Goddard Score $\geq 8$} \\
\hline DDR-original & 4.0 & 0.73 & 0.62 & 0.71 & $0.59-0.83$ \\
\hline DDR-simple & 0.09 & 0.60 & 0.90 & 0.73 & $0.62-0.85$ \\
\hline 6MWD (m) & 425 & 0.62 & 0.55 & 0.55 & $0.4 I-0.68$ \\
\hline Lowest $\mathrm{SpO}_{2}(\%)$ & 90 & 0.69 & 0.76 & 0.79 & $0.68-0.89$ \\
\hline \multicolumn{6}{|l|}{ PA:A ratio $>1$} \\
\hline DDR-original & 2.8 & 0.73 & 0.85 & 0.82 & $0.72-0.91$ \\
\hline DDR-simple & 0.1 & 0.73 & 0.82 & 0.83 & $0.73-0.92$ \\
\hline 6MWD (m) & 395 & 0.71 & 0.55 & 0.64 & $0.5 \mathrm{I}-0.77$ \\
\hline Lowest $\mathrm{SpO}_{2}(\%)$ & 89 & 0.85 & 0.72 & 0.86 & $0.77-0.95$ \\
\hline
\end{tabular}

Note: An ROC curve was judged as indicating high accuracy when AUC was $>0.7$. Abbreviations: ROC, receiver operating characteristic; AUC, area under the ROC curve; $\mathrm{Cl}$, confidence interval; $\mathrm{FEV}_{1.0}$, forced expiratory volume in the first second of expiration; $\mathrm{DLCO}$, diffusion capacity of the lung for carbon monoxide; PA, pulmonary artery; A, aorta; DDR, desaturation-distance ratio; 6MWD, six-minute walk distance; $\mathrm{SpO}_{2}$, peripheral oxygen saturation. 
95\% CI 0.72-0.91), DDR-simple (best cutoff point 0.1, AUC $0.83,95 \%$ CI 0.73-0.92), and lowest $\mathrm{SpO}_{2}$ (best cutoff point 89 , AUC 0.86, 95\% CI 0.77-0.95).

\section{Discussion}

We investigated the association among DDR, emphysema, and PH in stable COPD patients in this study. This study had two main findings. First, DDR showed to be correlated with emphysema and PH. Second, DDR-original and DDR-simple showed similar results in all the analyses. DDR may become an effective index to assess COPD with a high versatility because it can be calculated from the results of 6MWT used worldwide. Therefore, it was worth to find a new possibility of DDR in this study.

DDR was first proposed in 2010 as a new index for the assessment of interstitial lung diseases, ${ }^{19}$ with the simple version of DDR proposed in 2014 as an index for the assessment of the exercise capacity of COPD patients. ${ }^{20}$ These previous studies investigated the associations between DDR and $\% \mathrm{FEV}_{1.0}$ or $\% \mathrm{DLCO}$ but not associations between DDR and the indexes of emphysema and $\mathrm{PH} .{ }^{19,20}$ The present study demonstrated the further usefulness of DDR as an indicator of emphysema or PH in COPD patients. Unlike the individual outcomes of the 6MWT (6MWD and $\mathrm{SpO}_{2}$ ), DDR was related significantly with all of the parameters associated with COPD ( $\% \mathrm{FEV}_{1.0}, \% \mathrm{DLCO}, \% \mathrm{LAA}$, and PA:A ratio); DDR also demonstrated a strong ability to predict $\% \mathrm{FEV}_{1.0}<50 \%$, $\%$ DLCO $<75 \%$, Goddard Score $\geq 8$, and PA:A ratio $>1$. DDR could, therefore, become a useful index that reflects the degree of not only airflow obstruction and pulmonary diffusing capacity disorder but also emphysema and $\mathrm{PH}$, superior to both 6MWD and the lowest $\mathrm{SpO}_{2}$ individually.

Emphysema is a disorder that involves the destruction of alveoli caused by a decline in alveolar surface area and the elasticity of the lung. ${ }^{32,33}$ The destruction of alveoli progresses before symptoms appear or the lung function declines. ${ }^{34}$ Emphysema affects the patient's quality of life and is associated with exacerbations and deteriorating pulmonary function in subjects without airflow obstruction, even when the degree of emphysema is mild. ${ }^{7}$ It has been reported that $\mathrm{PH}$ can be caused by the combined results of hypoxia, inflammation, and capillary loss in emphysema ${ }^{35}$ and that there was an association of PH with exercise capacity and mortality in COPD patients. ${ }^{36,37}$ The early diagnosis of emphysema and $\mathrm{PH}$ is of great importance for COPD patients; however, it is not possible in practice to use $\mathrm{CT}$ or RHC for all patients or preliminary groups of COPD patients for the diagnosis of emphysema and PH. 6MWD and $\mathrm{SpO}_{2}$ can be measured noninvasively and easily, and it has been reported that 6MWD and EID were each related to emphysema and $\mathrm{PH} .{ }^{15-18} \mathrm{DDR}$, an index derived from combining 6MWD and EID, was shown in this study to be associated with \%LAA and PA:A ratio. Thus, it is suggested that DDR could become a useful index that indicates the extent of a patient's emphysema and $\mathrm{PH}$.

Both 6MWD and lowest $\mathrm{SpO}_{2}$, which are widely used as indexes of COPD conditions, showed significant correlations with \%DLCO, but neither showed a significant correlation with $\% \mathrm{FEV}_{1.0}$. This contrasted with previous studies, which demonstrated associations between 6MWD or lowest $\mathrm{SpO}_{2}$ and $\% \mathrm{FEV}_{1.0}{ }^{15,20} \mathrm{It}$ is speculated that these results may have been due to including subjects without airflow obstruction in the analysis. As evidence for this, 6MWD and lowest $\mathrm{SpO}_{2}$ showed significant correlations with $\% \mathrm{FEV}_{1.0}$ when only subjects with substantial airflow obstruction, indicated by $\mathrm{FEV}_{1.0} / \mathrm{FVC}<70 \%$, were included in the analysis. It has been reported that spirometry used to measure $\% \mathrm{FEV}_{1.0}$ underdiagnosed mild or early-stage COPD. ${ }^{38}$ Conversely, low DLCO was observed in ex-smokers without airflow obstruction, and DLCO has been known to be a sensitive index of early-stage COPD. ${ }^{3,39}$ In the present study, DDR showed significant correlations with both $\% \mathrm{FEV}_{1.0}$ and \%DLCO even when subjects without substantial airflow obstruction were included in the analysis. It is therefore suggested that DDR is superior to either 6MWD or lowest $\mathrm{SpO}_{2}$ individually in indicating COPD conditions, regardless of the degree of airflow obstruction.

Finally, the results for DDR-original and DDR-simple were similar in all the analyses. This suggests that DDRsimple is not inferior to DDR-original in screening COPD conditions. DDR-original requires a special device to record $\mathrm{SpO}_{2}$ continuously and analyze DA, whereas DDRsimple can be calculated using a conventional device such as a normal pulse oximeter. This makes DDR useful for the assessment of COPD patients in any situation, such as cases receiving medical treatment at home or at facilities other than hospitals, without the need for special devices.

This study had some limitations. First, it was a retrospective study at a single center, and the sample size was small. The influence of sex was not examined in this study, even though it has been reported that smoking affects women to a greater extent than men. Second, echocardiography was not performed for all the subjects, and medical history information regarding left ventricular dysfunction was not included in this study even though left ventricular dysfunction causes PA enlargement. These findings should be further 
inspected by a larger, ideal, multicenter, and prospective clinical trial that would take electrocardiography and ventricular function into consideration.

\section{Conclusion}

The results of this study suggested that DDR could be a useful index for the assessment of COPD patients. The 6MWT is an easy and low-cost method for the assessment of exercise capacity in these patients. DDR demonstrated a better ability than the other $6 \mathrm{MWT}$ measures to predict $\% \mathrm{FEV}_{1.0}<50 \%$, $\% \mathrm{DLCO}<75 \%$, Goddard Score $\geq 8$, and $\mathrm{PA}$ :A ratio $>1$, so its use could help with the early diagnosis of COPD.

\section{Acknowledgments}

The authors would like to thank the members of the Department of Rehabilitation, Kobe City Medical Center West Hospital, including Akihiro Honda, Chisato Nagatani, Takashi Kadooka, Shoko Mitani, Haruko Yamamoto, and Kumi Takamori for cooperation in acquisition of data, and the members of the Department of Community Health Sciences, Kobe University Graduate School of Health Sciences, including Akio Yamamoto, Kazuki Takahashi, Shigefumi Murakami, Kaoru Hanaie, Kentaro Iwata, Yoji Yamada, Yu Watanabe, Takuya Sawada, Kanji Yamada, Yusuke Iwata, Ken Umehara, and Keita Ohashi for constructive comments on this paper. The authors also thank Enago (Tokyo, Japan) for text correction.

\section{Author contributions}

Yukari Fujimoto involved in the conception and design of the study, acquisition of data, analysis and interpretation of data, and drafting the article. Yutaro Oki, Masahiro Kaneko, and Akira Ishikawa involved in the conception and design of the study, acquisition of data, analysis and interpretation of data, and revising the article. Hideki Sakai and Shogo Misu involved in the acquisition of data and revising the article. Takumi Yamaguchi, Yuji Mitani, and Hisafumi Yasuda involved in the conception and design of the study, interpretation of data, and revising the article. All authors contributed toward data analysis, drafting and critically revising the paper and agree to be accountable for all aspects of the work.

\section{Disclosure}

The authors report no conflicts of interest in this work.

\section{References}

1. Rabe KF, Hurd S, Anzueto A, et al; Global Initiative for Chronic Obstructive Lung Disease. Global strategy for the diagnosis, management, and prevention of chronic obstructive pulmonary disease: GOLD executive summary. Am J Respir Crit Care Med. 2007;176(6):532-555.
2. Pauwels RA, Rabe KF. Burden and clinical features of chronic obstructive pulmonary disease (COPD). Lancet. 2004;364(9434): 613-620.

3. Kirby M, Owrangi A, Svenningsen S, et al. On the role of abnormal $\mathrm{DL}(\mathrm{CO})$ in ex-smokers without airflow limitation: symptoms, exercise capacity and hyperpolarised helium-3 MRI. Thorax. 2013;68(8): 752-759.

4. de Torres JP, Bastarrika G, Wisnivesky JP, et al. Assessing the relationship between lung cancer risk and emphysema detected on low-dose CT of the chest. Chest. 2007;132(6):1932-1938.

5. Wilson DO, Weissfeld JL, Balkan A, et al. Association of radiographic emphysema and airflow obstruction with lung cancer. Am J Respir Crit Care Med. 2008;178(7):738-744.

6. Madani A, Zanen J, de Maertelaer V, Gevenois PA. Pulmonary emphysema: objective quantification at multi-detector row CT - comparison with macroscopic and microscopic morphometry. Radiology. 2006; 238(3):1036-1043.

7. Alcaide AB, Sanchez-Salcedo P, Bastarrika G, et al. Clinical features of smokers with radiological emphysema but without airway limitation. Chest. 2017;151(2):358-365.

8. Barberà JA. Mechanisms of development of chronic obstructive pulmonary disease-associated pulmonary hypertension. Pulm Circ. 2013; 3(1):160-164

9. Wells JM, Dransfield MT. Pathophysiology and clinical implications of pulmonary arterial enlargement in COPD. Int J Chron Obstruct Pulmon Dis. 2013;8:509-521.

10. Schulman LL, Lennon PF, Wood JA, Enson Y. Pulmonary vascular resistance in emphysema. Chest. 1994;105(3):798-805.

11. McLaughlin VV, Archer SL, Badesch DB, et al; ACCF/AHA. ACCF/ AHA 2009 expert consensus document on pulmonary hypertension: a report of the American College of Cardiology Foundation Task Force on Expert Consensus Documents and the American Heart Association: developed in collaboration with the American College of Chest Physicians, American Thoracic Society, Inc., and the Pulmonary Hypertension Association. Circulation. 2009;119(16): 2250-2294.

12. Wells JM, Washko GR, Han MK, et al; COPDGene Investigators; ECLIPSE Study Investigators. Pulmonary arterial enlargement and acute exacerbations of COPD. $N$ Engl J Med. 2012;367(10):913-921.

13. Iyer AS, Wells JM, Vishin S, Bhatt SP, Wille KM, Dransfield MT. CT scan-measured pulmonary artery to aorta ratio and echocardiography for detecting pulmonary hypertension in severe COPD. Chest. 2014;145(4):824-832.

14. Sciurba F, Criner GJ, Lee SM, et al; National Emphysema Treatment Trial Research Group. Six-minute walk distance in chronic obstructive pulmonary disease: reproducibility and effect of walking course layout and length. Am J Respir Crit Care Med. 2003;167(11):1522-1527.

15. Andrianopoulos V, Celli BR, Franssen FM, et al. Determinants of exercise-induced oxygen desaturation including pulmonary emphysema in COPD: results from the ECLIPSE study. Respir Med. 2016; 119:87-95.

16. Bodduluri S, Bhatt SP, Hoffman EA, et al; COPDGene Investigators. Biomechanical CT metrics are associated with patient outcomes in COPD. Thorax. 2017;72(5):409-414.

17. Nakahara Y, Taniguchi H, Kimura T, et al. Exercise hypoxaemia as a predictor of pulmonary hypertension in COPD patients without severe resting hypoxaemia. Respirology. 2017;22(1):120-125.

18. Oki Y, Kaneko M, Fujimoto Y, et al. Usefulness of the 6-minute walk test as a screening test for pulmonary arterial enlargement in COPD. Int J Chron Obstruct Pulmon Dis. 2016;11:2869-2875.

19. Pimenta SP, Rocha RB, Baldi BG, Kawassaki Ade M, Kairalla RA, Carvalho CR. Desaturation - distance ratio: a new concept for a functional assessment of interstitial lung diseases. Clinics (Sao Paulo). 2010; 65(9):841-846.

20. Ijiri N, Kanazawa H, Yoshikawa T, Hirata K. Application of a new parameter in the 6-minute walk test for manifold analysis of exercise capacity in patients with COPD. Int J Chron Obstruct Pulmon Dis. 2014;9: $1235-1240$. 
21. Paulin LM, Diette GB, Blanc PD, et al; SPIROMICS Research Group. Occupational exposures are associated with worse morbidity in patients with chronic obstructive pulmonary disease. Am J Respir Crit Care Med. 2015;191(5):557-565.

22. Regan EA, Lynch DA, Curran-Everett D, et al; Genetic Epidemiology of COPD (COPDGene) Investigators. Clinical and radiologic disease in smokers with normal spirometry. JAMA Intern Med. 2015; 175(9):1539-1549.

23. Harvey BG, Strulovici-Barel Y, Kaner RJ, et al. Risk of COPD with obstruction in active smokers with normal spirometry and reduced diffusion capacity. Eur Respir J. 2015;46(6):1589-1597.

24. Lutchmedial SM, Creed WG, Moore AJ, Walsh RR, Gentchos GE, Kaminsky DA. How common is airflow limitation in patients with emphysema on CT scan of the chest? Chest. 2015;148(1):176-184.

25. Pellegrino R, Viegi G, Brusasco V, et al. Interpretative strategies for lung function tests. Eur Respir J. 2005;26(5):948-968.

26. ATS Committee on Proficiency Standards for Clinical Pulmonary Function Laboratories. ATS statement: guidelines for the six-minute walk test. Am J Respir Crit Care Med. 2002;166(1):111-117.

27. Miller MR, Hankinson J, Brusasco V, et al; ATS/ERS Task Force Standardisation of spirometry. Eur Respir J. 2005;26(2):319-338.

28. Müller NL, Staples CA, Miller RR, Abboud RT. "Density mask". An objective method to quantitate emphysema using computed tomography. Chest. 1988;94(4):782-787.

29. Madani A, Van Muylem A, Gevenois PA. Pulmonary emphysema: effect of lung volume on objective quantification at thin-section CT. Radiology. 2010;257(1):260-268.

30. Bankier AA, De Maertelaer V, Keyzer C, Gevenois PA. Pulmonary emphysema: subjective visual grading versus objective quantification with macroscopic morphometry and thin-section CT densitometry. Radiology. 1999;211(3):851-858.
31. Goddard PR, Nicholson EM, Laszlo G, Watt I. Computed tomography in pulmonary emphysema. Clin Radiol. 1982;33(4):379-387.

32. Thurlbeck WM. Internal surface area and other measurements in emphysema. Thorax. 1967;22(6):483-496.

33. Finucane KE, Colebatch HJ. Elastic behavior of the lung in patients with airway obstruction. J Appl Physiol. 1969;26(3):330-338.

34. Pratt PC, Kilburn KH. A modern concept of the emphysemas based on correlations of structure and function. Hum Pathol. 1970;1(3): 443-463.

35. Chaouat A, Naeije R, Weitzenblum E. Pulmonary hypertension in COPD. Eur Respir J. 2008;32(5):1371-1385.

36. Sims MW, Margolis DJ, Localio AR, Panettieri RA, Kawut SM, Christie JD. Impact of pulmonary artery pressure on exercise function in severe COPD. Chest. 2009;136(2):412-419.

37. Cuttica MJ, Kalhan R, Shlobin OA, et al. Categorization and impact of pulmonary hypertension in patients with advanced COPD. Respir Med. 2010;104(12):1877-1882.

38. Shahab L, Jarvis MJ, Britton J, West R. Prevalence, diagnosis and relation to tobacco dependence of chronic obstructive pulmonary disease in a nationally representative population sample. Thorax. 2006;61(12): 1043-1047.

39. Klein JS, Gamsu G, Webb WR, Golden JA, Müller NL. High-resolution CT diagnosis of emphysema in symptomatic patients with normal chest radiographs and isolated low diffusing capacity. Radiology. 1992;182(3):817-821
International Journal of COPD

\section{Publish your work in this journal}

The International Journal of COPD is an international, peer-reviewed journal of therapeutics and pharmacology focusing on concise rapid reporting of clinical studies and reviews in COPD. Special focus is given to the pathophysiological processes underlying the disease, intervention programs, patient focused education, and self management protocols.

\section{Dovepress}

This journal is indexed on PubMed Central, MedLine and CAS. The manuscript management system is completely online and includes a very quick and fair peer-review system, which is all easy to use. Visit http://www.dovepress.com/testimonials.php to read real quotes from published authors. 